\title{
PEMETAAN POTENSI USAHA MASYARAKAT MELALUI PEMBENTUKAN KELOMPOK USAHA BERSAMA (KUBE) YANG KREATIF DAN INOVATIF DI DESA SUKARAJA, KECAMATAN JEROWARU, KABUPATEN LOMBOK TIMUR
}

Amalia Magfira1*, Rara Nabilla Arieno1, Ayu Yaminul Ainun1, Resti Apriliana1, Baiq Arum Kusumayati1, Resta Triana1, Ihza Abdi Ilahi1, I Made Wahyu Surya Pratama1, Jauhari Maknun1, Pandu Muslim1, M. Prasetyo Nugroho2.

1Mahasiswa KKN Universitas Mataram

2Prodi Peternakan Fakultas Peternakan Universitas Mataram

${ }^{*}$ Co-Author : amaliamagfira98@gmail.com

\begin{abstract}
ABSTRAK. Desa Sukaraja, Kecamatan Jerowaru, Kabupaten Lombok Timur merupakan daerah dengan potensi utama terletak pada sektor pertanian, khususnya jenis tanaman tembakau dan padi. Namun, pada sektor tersebut mengenal musim. Pada musim kemarau warga desa tidak bisa bercocok tanam. Oleh karena itu, guna mengisi kekosongan aktivitas bertani yang dilakukan pada musim tertentu, masyarakat desa membuat kerajinan anyaman rotan dan tidak sedikit warga yang membuka usaha perkiosan. Kendala yang dihadapi oleh masyarakat adalah kurangnya pengetahuan dan keahlian dalam mengembangkan potensi usaha yang mereka miliki. Potensi usaha, khususnya kerajinan anyaman seharusnya bisa menjadi ikon Desa Sukaraja bila dimaksimalkan usahanya. Namun, warga di sana membuat kerajinan anyaman menjadi bahan mentah, kemudian dibeli oleh pengepul dengan harga yang relatif murah dibandingkan harga yang dijual kembali oleh pengepul. Misalnya tas rotan, warga desa membuat bahan mentah, sedangkan pengepul menginovasi dengan menambahkan tali tas dan kain bagian dalam. Alternatif solusi yang dapat dilakukan untuk mengatasi kendala tersebut adalah dengan melakukan penyuluhan pengenalan apa itu kelompok usaha bersama (KUBe). Tujuan dari program ini adalah untuk mengubah pola pikir para pengulat (pembuat kerajinan anyaman) agar mau membentuk kelompok usaha bersama (KUBe) yang kreatif dan inovatif. Melalui kelompok tersebut, anggota kelompo bisa berkembang bersama dengan prakasarnya sendiri. Dengan harapan, warga bisa mengembangkan sendiri usaha kerajinan anyamannya, tidak hanya membuat dan menjual bahan mentah, tetapi langsung membuat produk jadi. Metode yang digunakan adalah persiapan program, sosialisasi pengenalan $\mathrm{KUBe}$, dan pembuatan serta pengantaran proposal permohonan dana usaha kepada Dinas Sosial setempat. Hasil dari program ini adalah terbentuknya kelompok usaha bersama (KUBe) di Desa Sukaraja serta diajukannya proposal permohonan dana usaha kepada Dinas Sosial Kabupaten Lombok Timur dan Dinas Sosial Provinsi Nusa Tenggara Barat.
\end{abstract}

Kata Kunci: Pemetaan usaha, kelompok usaha bersama, Desa Sukaraja

ABSTRACT. Sukaraja Village, Jerowaru District, East Lombok Regency is an area with the main potential located in the agricultural sector, especially the types of tobacco and rice. However, the sector is familiar with the season. In the dry season the villagers cannot plant crops. Therefore, in order to fill the void of farming activities carried out in certain seasons, villagers make rattan wicker handicrafts and not a few residents open a ventilation business. The obstacle faced by the community is the lack of knowledge and expertise in developing the business 
potential they have. The business potential, especially woven crafts, should be able to become an icon of Sukaraja Village if its business is maximized. However, residents there make woven crafts into raw materials, then are bought by collectors at a price that is relatively cheap compared to the prices resold by collectors. For example rattan bags, villagers make raw materials, while collectors innovate by adding bag straps and inner cloth. An alternative solution that can be done to overcome these obstacles is by conducting an introduction to what a joint business group (KUBe) is. The purpose of this program is to change the mindset of the wrestlers (makers of woven crafts) so they want to form creative and innovative joint venture groups (KUBe). Through this group, members of the group can develop together with their own pre-market. With hope, residents can develop their own woven handicraft business, not only making and selling raw materials, but directly making finished products. The method used is program preparation, socialization of KUBe introduction, and preparation and delivery of proposals for business funds to the local Social Service. The results of this program were the formation of a joint business group (KUBe) in Sukaraja Village and the submission of proposals for business funds.

Keyword: Business mapping, joint venture groups, Sukaraja Village

\section{PENDAHULUAN}

Anyaman adalah serat yang dirangkaikan hingga membentuk benda yang kaku, biasanya untuk membuat keranjang atau perabot. Anyaman sering kali dibuat dari bahan yang berasal dari tumbuhan, tetapi serat plastik juga dapat digunakan. Bahan yang digunakan bisa bagian apapun dari tanaman, misalnya inti batang tebu atau rotan atau keseluruhan ketebalan tanaman, seperti misalnya dedalu. Bahan lainnya yang terkenal digunakan sebagai anyaman adalah gelagah dan bambu. Biasanya rangkanya dibuat dari bahan yang lebih kaku, setelah itu bahan yang lebih lentur digunakan untuk mengisi rangka. Anyaman bersifat ringat tetapi kuat, menjadikannya cocok sebagai perabot yang sering dipindah-pindah. Anyaman sering digunakan untuk perabot di beranda dan teras. Namun, seiring dengan perkembangan zaman menyebabkan eksistensi anyaman semakin berkembang. Hal itu terlihat pada bentuk anyaman yang semakin beragam dan diminati. Salah satu bentuk anyaman yang paling diminati oleh kaum milenial adalah anyaman tas rotan.

Berbagai bentuk anyaman ini dibuat oleh masyarakat Desa Sukaraja. Meskipun bukan pekerjaan utama, namun potensi anyaman sangat besar di desa ini. Hampir setiap rumah menghasilkan anyaman dengan bentuk yang beragam. Pekerjaan ini pun tidak mengenal musim, karena warga bisa menganyam di manapun dan kapanpun. Hampir semua kalangan yang ada di Desa Sukaraja bisa membuat anyaman. Warga Desa Sukaraja melakukan aktifitas ini ketika memiliki waktu luang. Terlihat di setiap rumah terdapat saja warga yang duduk menganyam.

Pada dasarnya kerajinan anyaman ini menjadi potensi yang besar, namun tidak dikelola dan dimanfaatkan dengan baik oleh pihak desa. Hal itu menjadi masalah yang disayangkan. Warga Desa Sukaraja membuat anyaman menjadi anyaman yang masih mentah, kemudian dibeli oleh pengepul dengan harga yang cukup murah yaitu sekitar Rp20,000 hingga Rp35,000 ke atas, sesuia dengan ukuran. Pada akhirnya, pengepul menjual anyaman tersebut dengan harga 2 kali lipat dari harga yang dibeli pada warga desa. Misalnya anyaman tas, hanya dengan menambahkan tali dan 
kain pada bagian dalam, pengepul menjual tas dengan harga 2 kali lipat. Pengepul membeli dengan harga Rp35,000 kemudian setelah dipoles akan dijual dengan harga Rp85,000 hingga ratusan ribu ke atas.

\section{METODE}

\section{Waktu dan Tempat}

Kegiatan dilakukan setiap minggu, dimulai sejak tanggal 26 Desember 2019 sampai dengan 06 Februari 2020 di Desa Sukaraja, Kecamatan Jerowaru, Kabupaten Lombok Timur.

\section{Prosedur Pembentukan Kelompok Usaha Bersama (KUBe)}

Selama kegiatan KKN telah dilakukan survei untuk melihat usaha apa saja yang ada di Desa Sukaraja. Adapun hasil yang diperoleh ialah terdapat usaha perkiosan, usaha kerajinan anyaman, usaha kerajinan tenun, ruko, dan usaha mikro lainnya. Namun, yang paling mendominasi adalah kerajinan anyaman. Hampir di setiap rumah terdapat warga yang membuat kerajinan anyaman. Mereka yang bergelut di bidang tersebut disebut pengulat.

Sebelum mengadakan acara sosialisasi, terlebih dahulu anggota KKN berkunjung ke rumah Kepala Dusun guna menanyakan kelompok usaha yang dimiliki oleh warga. Namun, kelompok usaha yang ada hanya kelompok usaha tani. Pada tanggal 24 Januari 2020, anggota KKN mengantar surat undangan sosialisasi kepada Kepala Dusun se-Desa Sukaraja dan surat permintaan menjadi pemateri sosialisasi kepada TKSK Jerowaru.

Pada tanggal 27 Januari 2020 diadakanlah sosialisasi pengenalan kelompok usaha bersama (KUBe) di Aula Kantor Desa Sukaraja. Adapun topik sosialisasi adalah "Membentuk Kelompok Usaha Bersama (KUBe) yang Kreatif dan Inovatif untuk Meningkatkan Taraf Ekonomi Kelompok". Acara ini dihadiri oleh Kepala Desa Sukaraja, Bapak Ahmad Zaenuri AW., Kepala Dusun se-Desa Sukaraja, dan puluhan warga desa. Pemateri pada sosialisasi ini adalah Bapak Jumedan Hasyri selaku TKSK Jerowaru. Tujuan dari soalisasi ini adalah untuk mengenalkan KUBe kepada masyarakat, dengan harapan mereka akan berminat membentuk sebuah kelompok usaha bersama.

Setelah kegiatan sosialiasasi berlangsung, dihimbaukan kepada warga desa yang berminat membentuk KUBe agar menyiapkan syarat-syarat pembentukan kelompok seperti fotokopi KTP, KK, KKS jika ada. Pada hari yang sama, Kepala Dusun Montong Kelek dan Bare Tengak menginformasikan ingin membetuk KUBe. Oleh karena itu, dibentuklah 2 kelompok usaha bersama, yaitu KUBe Patuh Angen dan KUBe Karya Bakti.

\section{Bentuk Kegiatan}

Bentuk kegiatan secara keseluruhan ini adalah 1) Persiapan program, 2) Sosialisasi pengenalan KUBe, 3) Pembentukan Kelompok Usaha Bersama (KUBe), 4) Pembuatan proposal permohonan dana usaha, dan 5) Pengantaran proposal permohonan dana kepada Dinas Sosial Kabupaten Lombok Timur dan Dinas Sosial Provinsi Nusa Tenggara Barat.

\section{HASIL DAN PEMBAHASAN}

Program pemetaan potensi usaha melalui pembentukan kelompok usaha bersama di Desa Sukaraja dilakukan secara terstruktur dan melibatkan masyarakat secara langsung. 


\section{Pelaksanaan Sosialisasi}

Kegiatan sosialisasi ini dimulai dengan persiapan progran yang meliputi survei lokasi sosialisasi, penentuan waktu dan tempat, serta pencarian materi sosialisasi. Pada mulanya, anggota KKN mengantarkan surat permohonan narasumber kepada Dinas Sosial Kabupaten Lombok Timur, tetapi pihak Dinas Sosial berhalangan. Oleh karena itu, ditemuilah TKSK Jerowaru. Pada hari Senin, 27 Januari 2020 diselenggarakanlah acara sosialisasi tersebut dengan lancar.

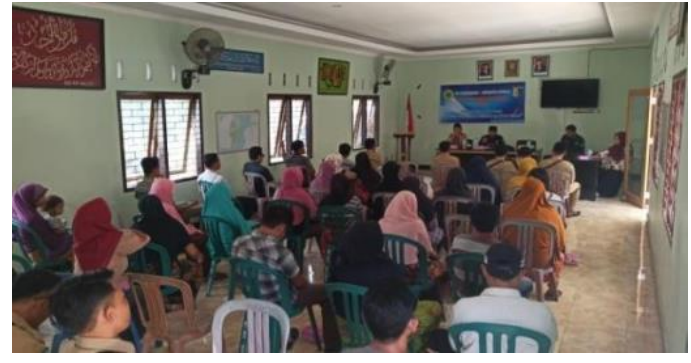

Gambar 1. Pelaksanaan sosialisasi pembentuka KUBe

\section{Pembentukan Kelompok Usaha Bersama (KUBe) di Desa Sukaraja}

Kelompok usaha bersama (KUBE) adalah himpunan dari keluarga dengan jumlah anggota kepala keluarga $10 \mathrm{KK}$ yang tergolong masyarakat miskin. Kelompok tersebut dibentuk, tumbuh, dan berkembang atas dasar prakarsanya sendiri, saling berinteraksi antara satu dengan yang lain, serta tinggal dalam satuan wilayah tertentu. Kelompok usaha ini akan menerima bantuan dana dari pemerintah dengan criteria penerima bantuan; keluarga fakir miskin atau miskin dan masuk dalam BDT (Basis Data Terpadu); berusia antara 18-59 tahun dan sudah menikah; berdomisili tetap dan berdekatan; memiliki potensi dan keterampilan di bidang $\mathrm{KUBe}$, tidak boleh PNS, TNI/POLRI, maupun pensiunan.

Berdasarkan pemaparan di atas, etelah dilaksanakannya program sosialisasi pengenalan KUBe pada tanggal 27 Januari 2020, terbentuklah 2 kelompok usaha. bersama. Kelompok usaha tersebut ialah KUBe Patuh Angen dan KUBe Karya Bakti. Dengan harapan, kelompok usaha tersebut akan tumbuh dan berkembang sesuai prakarsa anggota kelompok sendiri. Selain itu, dengan adanya kelompok usaha tersebut masyarakat bisa mengembangkan usahanya menjadi usaha yang kreatif dan inovatif sehingga pendapatan bisa bertambah. Dengan kata lain bisa memperbaiki kehidupan ekonominya.

\section{Penetapan Pengurus Kelompok Usaha Bersama (KUBe)}

1) KUBe dengan nama kelompok Patuh Angen berasal dari Dusun Bare Tengak, Desa Sukaraja. Patuh Angen artinya sama rasa atau satu hati. Usaha yang digeluti ialah usaha Mikro Bersama (Kerajinan Anyaman dan Perkiosan). Kelompok ini merupakan kelompok usaha gabungan antara pedagang kios dan pengulat. Kelompok usaha Patuh Angen terdiri atas 10 anggota. Adapun struktur organisasi kelompok sebagai berikut.

Ketua : Masguni

Sekretaris : Serun

Bendahara : Muksin

Anggota : Sinep, Sebah, Rinasi, Melati, Miasi, Asiah, Kirin. 
Penetapan pengurus kelompok Patuh Angen ditetapkan langsung setelah pembentukan KUBe.

2) KUBe yang bernama Karya Bakti. KUBe ini merupakan kelompok usaha bersama yang beralamat di Dusun Montong Kelek, Desa Sukaraja. Kelompok Usaha Bersama (KUBe) Karya bakti bergelut di bidang usaha kerajinan anyaman rotan. Oleh karena itu, keseluruhan anggota bisa disebut sebagai pengulat. KUBe Karya Bakti terdiri atas 10 anggota dengan struktur organisasi kelompok sebagai berikut.
Ketua
: Sibang Waihi
Sekretaris
: Nurasi
Bendahara
: Muslim
Anggota $\quad$ : Lanep Jumerep, Mahzan, Minasi, Ginasih, Sanep, Masri.

Penetapan pengurus kelompok ditetapkan di rumah Kepala Dusun Montong Kelek yang dihadiri oleh seluruh anggota kelompok. Oleh karena itu, penetapan ini dilakukan atas dasar kesepakatan bersama.
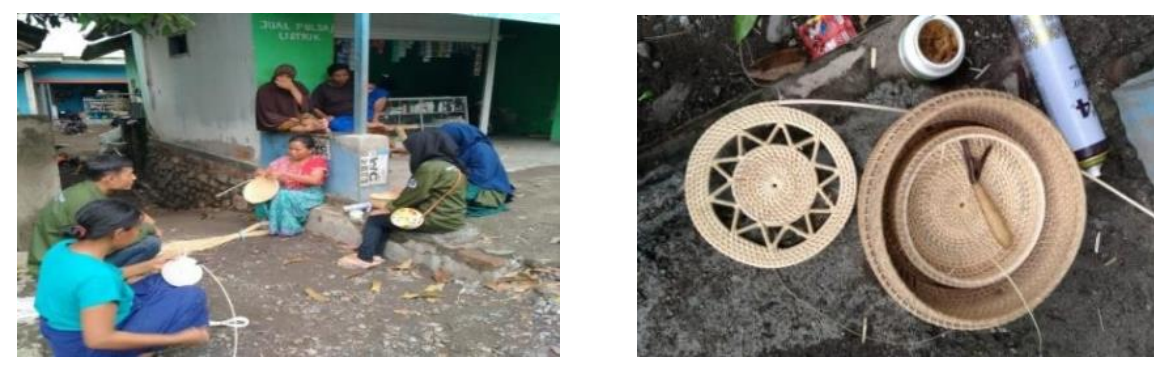

Gambar $1 . \quad$ Hasil kerajinan anyaman

Pembuatan dan Pengantaran Proposal

Permohonan Dana Bantuan Usaha

Pembuatan proposal ini merupakan salah satu bentuk usaha mahasiswa KKN dalam membantu kelompok usaha yang telah terbentuk. Selain itu, proposal ini juga merupakan bukti adanya kelompok usaha bersama yang telah dibentuk oleh mahasiswa KKN setelah melakukan program sosialisasi pengenalan KUBe.

Proposal yang dibuat ialah 2 macam proposal dengan format yang berbeda. Kedua proposal tersebut kemudian diantarkan kepada Dinas Sosial Kabupaten Lombok Timur dan Dinas Sosial Provinsi Nusa Tenggara Barat.

\section{SIMPULAN}

Simpulan dari program sosialisasi dan pemetaan potensi usaha melalui pembentukan Kelompok Usaha Bersama (KUBe) ini adalah masyarakat Desa Sukaraja dapat memperbaiki kehidupan ekonominya sehingga eksistensi masyarakat miskin bisa berkuran. Pembentukan KUBe ini pun merupakan salah satu wadah bagi pemerintah untuk menyalurkan dana bantuan usaha guna mengentaskan kemiskinan. Dengan membentuk suatu kelompok usaha bersama, diharapkan warga dapat mengembangkan usahanya agar menjadi usaha yang kreatif dan inovatif sehingga usaha bisa berlanjut dan membuahkan hasil bagi kelompok maupun desa. Tentu saja hal ini dilakukan atas dasar keinginan dan keterampilan anggota kelompok itu sendiri. 


\section{Jurnal Warta Desa}

www.jwd.unram.ac.id

\section{UCAPAN TERIMA KASIH}

Kami menyadari bahwa terlaksananya program-program yang telah dilaksanakan bukanlah keberhasilan individu melainkan kelompok atas bantuan dari beberapa pihak. Oleh karena itu, kami mengucapkan terima kasih kepada Bapak M. Prasetyo Nugroho, S.Pt., M.Si., selaku dosen pembimbing lapangan KKN Pemberdayaan Universitas Mataram di Desa Sukaraja, Kecamatan Jerowaru, Kabupaten Lombok Timur., Bapak Ahmad Zaenuri AW., selaku Kepala Desa Sukaraja Bapak Ruslan, S.Kom., selaku Sekretaris Desa Sukaraja. Bapak Bintara Pembina Desa Sukaraja.Stafstaf Desa Sukaraja. Bapak Kepala Dusun se-Desa Sukaraja. Seluruh masyarakat Desa Sukaraja. Semua pihak yang telah membantu selama kegiatan KKN.

\section{REFERENSI}

Ika, Febriana Permata. (2015). Pemberdayaan Keluarga Melalui Kelompok Usaha Bersama (KUBE) di Dusun Gamol, Desa Balecatur, Gamping, Sleman Yogyakarta. Yogyakarta: Universitas Negeri Yogyakarta. Diakses pada tanggal 9 Februari 2020.

Ningrum, Diah Ayu. (2017). Peran Kelompok Usaha Bersama (KUBE) dalam Menangani Kemiskinan di KUBE Sejahtera Desa Giripurno, Ngadirejo, Temanggung. Yogyakarta: Universitas Negeri Yogyakarta. Diakses pada tanggal 9 Februari 2020.

Afriyandi, Yuli. (2015). Lembaga Keuangan Mikro Berbasis Kelompok Usaha Bersama; Sebuah Strategi Pengentasan Kemiskinan Struktural. Journal of Islamic Economics Lariba. Volume 1, Issue 1, 2015. Diakses pada tanggal 9 Februari 2020.

Sari, Purnama. (2017). Kelompok Usaha Bersama (KUBE) dalam Rangka Pemberdayaan Masyarakat Prasejahtera. Jurnal IImiah IImu Pemerintahan 3 (2), 99-107, 2017. Diakses pada tanggal 9 Februari 2020.

Effendi, Arif. (2014). Franchise Sebagai Strategi dalam Pengembangan Usaha Mikro, Kecil, dan Menengah di Indonesia. Yogyakarta: Deepublish, h 25. 